\title{
A mobile interventional radiology unit: innovation and social responsibility
}

\author{
Unidade de radiologia intervencionista móvel: inovação e responsabilidade social
}

\author{
Nestor Hugo Kisilevzky ${ }^{1}$, Henrique Elkis ${ }^{2}$, Francielle Aparecida Gusmao ${ }^{3}$
}

\begin{abstract}
Objective: To present the preliminary results of a feasibility study performed to determine the value of a mobile interventional radiology unit used to promote a uterine embolization program for low-income patients. Methods: Forty patients with symptomatic fibroids were treated with uterine embolization. Procedures were performed in four public hospitals in the metropolitan area of Sao Paulo. This study was approved by the institutional research ethics committee and all patients signed an informed consent form. A mobile interventional radiology unit, named ANGIOMOVEL, was conceived and implemented utilizing a small truck to transport one mobile $\mathrm{C}$ arm, one radiological table, protection aprons and a small trolley containing specific supplies for the procedures. The ANGIOMOVEL team consisted of two interventional radiologists, one nurse, one driver and one assistant. The unit visited one hospital per week during a three-month period. Patient inclusion was contingent upon several factors, such as evaluation by a trained gynecologist, completion of a pelvic MRI, routine serological laboratory tests and completion of a quality of life questionnaire (0OL). Outcomes, MRI and $\mathrm{OOL}$ were evaluated. Data obtained after 12 weeks were collected and analyzed. Results: Technical success was achieved in $100 \%$ of cases, with a mean procedure time of 43 minutes and a mean fluoroscopic time of 24 minutes. The mean hospital stay was 1.07 day and the mean time for recovery and return to normal activities was 10 days. After 12 weeks, 36 (90\%) of patients noticed improvement of their symptoms and $4(10 \%)$ did not notice any improvement. Thirty-eight patients $(95 \%)$ were satisfied or very satisfied and $39(97.5 \%)$ said they would recommend the procedure. Pre- and post-procedure magnetic resonance imaging analysis showed that complete fibroid ischemia was achieved in $92.5 \%$ of cases with a mean uterine volume reduction of $38 \%$ and a mean fibroid volume reduction of $52 \%$. Health-related quality of life scores showed improvement, increasing from 39.30 before the treatment
\end{abstract}

to 79.62 points after therapy. Conclusions: The initial results indicate that using a Mobile Interventional Radiology Unit is feasible, efficient and safe to develop a successful uterine fibroid embolization program providing care to the underserved patient community.

Keywords: Myoma/radiotherapy; Radiology, interventional; Mobile health units; Mobile health units/supply \& distribution; Uterine artery embolization; Uterine artery embolization/utilization; Uterine artery embolization/economics; Social responsibility; Quality of life; Hospitals, public; Women's health services; Women's health services/ supply \& distribution; Women

\section{RESUMO}

Objetivo: Apresentar os resultados preliminares de um estudo de viabilidade conduzido para determinar 0 valor de uma unidade de radiologia intervencionista móvel com o objetivo de promover um programa de embolização uterina em mulheres de baixa renda. Métodos: Quarenta pacientes portadoras de miomatose sintomática foram tratadas com embolização uterina. Os procedimentos foram realizados em quatro hospitais públicos localizados na área metropolitana de São Paulo. 0 estudo foi aprovado pelo Comitê de Ética em Pesquisa da Instituição e todos os pacientes assinaram um termo de consentimento informado. Uma unidade de radiologia intervencionista móvel denominada ANGIOMÓVEL foi concebida e implementada utilizando um caminhão baú para transportar um arco cirúrgico, uma mesa radiológica, aventais de chumbo e um pequeno carro contendo os insumos específicos para os procedimentos. A equipe do ANGIOMÓVEL consistiu de dois radiologistas intervencionistas, uma enfermeira, um motorista e um assistente. A unidade visitou um hospital por semana durante três meses. A inclusão de pacientes dependeu de vários fatores como avaliação por um ginecologista treinado, realização de um

\footnotetext{
Study carried out at Hospital Israelita Albert Einstein - HIAE, São Paulo (SP), Brasil.

'Master's degree in Surgery; MD, Specialist in interventionist radiology, Hospital Israelita Albert Einstein - HIAE, São Paulo (SP), Brazil.

${ }^{2}$ Master's degree in Surgery; MD, Specialist in interventionist radiology, Hospital Israelita Albert Einstein - HIAE, São Paulo (SP), Brazil.

${ }^{3}$ Nurse of Instituto Israelita de Responsabilidade Social Albert Einstein - HIAE, São Paulo (SP), Brazil.

Corresponding author: Nestor Hugo Kisilevzky - Rua Guararapes, 682 - Lapa - CEP 05077-051 - São Paulo (SP), Brasil - Tel.: 11 3285-6161 - e-mail: kisilevn@uol.com.br

Received on June 14, 2009 - Accepted on Dec 12, 2009

There is no conflict of interest
} 
exame de ressonância magnética da pelve, exames laboratoriais de rotina e resposta a um questionário para avaliação da qualidade de vida (OV). Evolução clínica, ressonância magnética e QV foram avaliadas. A informação obtida após 12 semanas foi colhida e analisada. Resultados: Verificou-se $100 \%$ de sucesso técnico para realização da embolização. 0 tempo médio de procedimento foi de 43 minutos com tempo médio de fluoroscopia de 24 minutos. 0 tempo médio de internação foi de 1,07 dias e a retomada das atividades ocorreu numa média de 10 dias. Após 12 semanas, 36 pacientes $(90 \%)$ referiram estar clinicamente melhor e $4(10 \%)$ não tiveram melhora. Trinta e oito pacientes (95\%) manifestaram estar satisfeitas ou muito satisfeitas, e $39(97,5 \%)$ recomendariam 0 tratamento. Na análise das ressonâncias magnéticas pré o pósoperatórias, verificou-se uma redução de volume uterino de $38 \%$ e redução de volume no mioma dominante de $52 \%$. Verificou-se ainda que a necrose isquêmica completa dos miomas foi causada em $92,5 \%$. A análise dos questionários de vida demonstrou uma melhora significativa passando de um escore de 39,30 pontos antes do tratamento para 79,62 pontos após o tratamento. Conclusões: Os resultados preliminares indicam que a utilização de uma Unidade de Radiologia Intervencionista Móvel é viável, eficiente e segura para promover um programa de embolização uterina em pacientes que dependem exclusivamente do atendimento em hospitais da rede pública.

Descritores: Mioma/radioterapia; Radiologia intervencionista; Unidades móveis de saúde; Unidades móveis de saúde/provisão \& distribuição; Embolização da artéria uterina; Embolização da artéria uterina/utilização; Embolização da artéria uterina/economia; Responsabilidade social; Qualidade de vida; Hospitais públicos; Serviços de saúde da mulher; Serviços de saúde da mulher/provisão \& distribuição; Mulheres

\section{INTRODUCTION}

Since the first article on uterine embolization was published in the medical literature, in $1995^{(1)}$, much has been learned about this innovative treatment. The great amount of scientific articles published in the past 13 years led the American College of Obstetricians and Gynecologists (ACOG) to recently publish a practical newsletter acknowledging uterine embolization as Scientific Evidence Level A: good and consistent ${ }^{(2)}$. In Brazil, uterine embolization technique has gained support lately and has been used for nearly ten years, mainly by health insurance programs $^{(3)}$. Since it is a procedure that demands appropriate technology, specific inputs and qualified human resources, it is not a technique provided routinely to patients that depend on the public health system in Brazil. Certainly, hysterectomy is the management most disseminated for symptomatic fibroids in public health services. Trying to universalize access of low-income patients to medical technology, the idea of developing a mobile interventional radiology unit was put forward. The unit could move to different sites and provide treatment - uterine embolization - to women with symptomatic fibroids, at public hospitals of the metropolitan area of Sao Paulo. Since there is no literature on this concept, it was decided to investigate its feasibility by means of this scientific study.

\section{OBJECTIVE}

To present the preliminary results of a study on feasibility of developing a mobile interventional radiology unit.

\section{METHODS}

This is a prospective and descriptive longitudinal study that was submitted to and approved by the Research Ethics Committee (CEP) of the Hospital Israelita Albert Einstein. All patients signed an informed consent form.

In the period from October 17, 2008 to January 16, 2009, 40 patients with uterine fibroid were treated by embolization technique. The procedures were performed in four public hospitals of the metropolitan area of Sao Paulo: Hospital Leonor Mendes de Barros, Complexo Hospitalar Mandaqui, Hospital Regional de Cotia and Hospital Universitário de Jundiaí. A mobile interventional radiology unit, named ANGIOMOVEL, was developed using a small truck to transport one mobile C arm (Philips BV Pulsera), one radiological table, protection aprons and trolleys containing supplies needed for angiographic exams and embolization procedures. The ANGIOMOVEL team consisted of two physicians specialized in interventional radiology (NK and $\mathrm{HE}$ ), one nurse (FG), one driver and one assistant. The ANGIOMOVEL team made nine visits in this period. Each hospital visited provided an empty room in the operation theater or obstetric center, where the equipment was placed and the procedure room was temporarily prepared for embolization. The patients were selected by the gynecology team of each hospital based on the protocol approved by the CEP. The inclusion criteria were patients with symptomatic fibroids, regardless of size, number or location of myomatous nodule, aged between 25 and 50 years. All patients were previously submitted to clinical and laboratory exams, including magnetic resonance imaging (MRI). They also answered a validated questionnaire to determine the impact of symptoms on their quality of life ${ }^{(4)}$. All the procedures were performed under epidural anesthesia. Calibrated microspheres were used as embolism agents (BioSphere $\left.\mathrm{Med}^{\circledR}\right)$. The angiographic studies were performed with non- 
ionic contrast (Iopamiron $300^{\circledR}$ ). Patients remained hospitalized under care of the gynecology team. After discharge, they were oriented to go to the interventional radiology outpatient's clinic. The following variables were investigated: length of stay, delay to resume activities after surgery, perception of symptoms and level of satisfaction. The women were also asked if they would recommend the procedure. All patients were asked to have a magnetic resonance imaging exam 12 weeks after embolization in order to check the grade of ischemia caused in fibroids and the reduction in volume of the uterus and of the predominant fibroid. They also filled in once again the questionnaire on quality of life, and the answers were compared to those given before the procedure. All data collected were input in a Microsoft Excel worksheet and analyzed through simple descriptive statistical methods.

\section{RESULTS}

The embolization procedure was successfully performed in all 40 patients $(100 \%)$ and no technical complication was observed. The mean procedure time was 43 minutes (17 to 140 minutes) and the mean fluoroscopy time (radiation) was 24 minutes (8 to 53 minutes).

In average, $150 \mathrm{ml}$ of radiological contrast medium was used (50 to $350 \mathrm{ml})$ and 2.3 vials of embolization microspheres (1 to 7 vials).

All patients, except two, (95\%) were admitted to hospital for just one day, one patient stayed for 2 days and another, for 3 days. The mean hospital stay was 1.07 days.

The mean time to fully resuming activities was 10 days ( 2 to 30 days). In the postoperative clinical follow-up, 36 patients $(90 \%)$ reported improved symptoms and 4 remained with the same symptoms presented before treatment. As to level of satisfaction, 28 patients were very satisfied $(70 \%), 10$ were satisfied (25\%) and two were dissatisfied (5\%). Comparing the scores obtained by the questionnaires on quality of life, there was a significant change. The mean score related to severity of symptoms dropped from 58.6 in the preoperative period to 15.46 after therapy (the higher the score, the more severe symptoms) and the score regarding quality of life as a whole rose from 39.3 in the preoperative period to 87.06 after treatment (the higher the score, the better quality of life).

Analyzing the pre- and postoperative MRI examinations, complete ischemia of fibroids (purpose of embolization) was observed in 37 cases (92.5\%). The mean uterine volume decreased from 396 cubic centimeters (cc) before treatment to $245 \mathrm{cc}$ after therapy, accounting for a reduction of $38 \%$. The mean volume of the predominant fibroids dropped from 112 cc before treatment to $54 \mathrm{cc}$ after therapy, representing a $52 \%$ reduction.

MRI demonstrated total elimination of submucous fibroids in five patients. The postoperative clinical complications (30 days) included three re-admissions to treat pain, one re-admission for assisted removal of necrotic intrauterine fibroid (delivery), and one hematoma on the site of arterial punction with no need for further therapy.

\section{DISCUSSION}

Uterine embolization is a technique approved all over the world as an alternative therapy of uterine fibroids. Several scientific articles on this topic have been published emphasizing the advantages and benefits of the procedure, including many randomized studies comparing embolization and other types of treatment ${ }^{(5-9)}$.

Hence, the objective of this study was not to address uterine embolization as one type of treatment, but rather to discuss the concept of a Mobile Interventional Radiology Unit.

Among the public hospitals in the metropolitan area of São Paulo, few of them provide interventional radiology services and even fewer routinely offer uterine embolization.

Trying to improve this scenario, the concept of "sharing medical technology" was suggested by setting a mobile unit to provide care in several institutions and different places. The concept of mobile health unit is not new, and many experiences were reported in diverse fields of medicine ${ }^{(10-12)}$. Nevertheless, in Interventional Radiology, this concept is quite bold and absolutely innovative. This could be potentially possible thanks to the development of state-of-the-art portable radiological devices (C-arms), which provide image quality and information technology resources that are compatible and sufficient to perform interventional radiology procedures in an efficient and safe manner. The idea was to explore the main feature of this equipment: its mobility.

Uterine embolization was chosen as a model for being a very simple method with little technical variables that would fit a model for mobile care unit. However, since it is an absolutely new experience, it had to be tested by means of a feasibility study.

The primary and secondary endpoints were determined to establish safety and efficacy of treatment using this methodology. Given that the objective of uterine embolization is to cause complete ischemia of fibroids and, therefore, to 
attenuate or eliminate uncomfortable symptoms, the main criteria of efficacy were clinical progression and anatomical changes evaluated by MRI. Since symptoms related to fibroid are generally very subjective (bleeding volume, intensity of pain, discomfort caused by occupying space, etc.) and considering it is an absolutely benign condition, the concept of impact on quality of life was used to assess clinical progression. Hence, the results obtained are corroborated by those extensively reported in the literature ${ }^{(13)}$.

Obviously, the clinical results are directly related to technical results, which consist of the object of our analysis in this study. The guidelines prepared and published by the Society of Interventional Radiology, in the United States, recommend a threshold of $96 \%$ for technical success in uterine embolization, when the procedures are performed in conventional rooms, with fixed digital subtraction angiography equipment $^{(14)}$. In our experience, we could complete uterine embolization in all cases, even working with a portable equipment. One important fact to consider in uterine embolization is that the pelvis is exposed to radiation, which could cause some negative impact on the ovarian function. This possibility is directly related to duration of the procedure and primarily to radiological exposure time of fluoroscopy. Some previously published studies indicated the mean safe radiation time for uterine embolization would be 25 minutes, which in terms of radiation dose is similar to contrasted radiological exam of bowels ${ }^{(15-16)}$. Thus, our technique respected these principles even under different conditions.

Safety of treatment is evaluated by frequency of negative outcomes. It has already been reported that postoperative complications of the uterine embolization are not frequent and severe ${ }^{(17)}$. Our experience was not different; therefore, it could be said the treatment was absolutely safe.

Lastly, it is noteworthy mentioning the new concept this experience brought to our practice as healthcare professionals. Used to provide care, to develop clinical or experimental research and to work with educational and training programs, we now acquire this new idea to our practice: the concept of social responsibility, which means to direct our expertise and part of our working time to benefit those who have no access to our activity on a daily basis. This will definitely reinforce our identity and develop our profession.

\section{CONCLUSIONS}

The preliminary results of the study indicate that the use of a mobile interventional radiology unit is feasible, efficient and safe to promote a uterine embolization program at public hospitals that do not offer such technology. It is an alternative to give access to state-ofthe-art technology to low-income women for treating fibroids. And it is definitely a social responsibility activity aiming to provide more for these less favored citizens.

\section{ACKNOWLEDGEMENTS}

The authors would like to thank the support given by Instituto Israelita de Responsabilidade Social Albert Einstein, and the companies Philips, Bayer-ScheringPharma and BioSphere Medical for making this study possible.

\section{REFERENCES}

1. Ravina JH, Herbreteau D, Ciraru-Vigneron N, Bouret JM, Houdart E, Aymard $A$, et al. Arterial embolisation to treat uterine myomata. Lancet. 1995;346(8976):671-2.

2. ACOG. Alternatives to hysterectomy in the management of leiomyomas. ACOG Practice bulletin. 2008;96(1):387-400.

3. Kisilevzky NH, Martins MS. Embolização uterina para tratamento de mioma sintomático: experiência inicial revisão da literatura. Radiol Bras. 2003;36(3):129-40.

4. Kisilevzky N. Embolização uterina para tratamento de miomas sintomáticos: impacto na qualidade de vida. Radiol Bras. 2007;40(5):289-96.

5. Smith WJ, Upton E, Shuster EJ, Klein AJ, Schwartz ML. Patient satisfaction and disease specific quality of life after uterine artery embolization. Am J Obstet Gynecol. 2004;190(6):1697-703; discussion 1703-6.

6. Lohle PN, Boekkooi FP, Smeets AJ, Pieters, JJ, Vervest HA, Lampmann $\mathrm{LE}$, et al. Limited uterine artery embolization for leiomyomas with tris-acryl gelatin microspheres: 1-year follow-up. J Vasc Interv Radiol. 2006;17(2 Pt 1): 283-7.

7. Pinto I, Chimeno P, Romo A, Paúl L, Haya J, de la Cal MA, et al. Uterine fibroids: uterine artery embolization versus abdominal hysterectomy for treatment: a prospective, randomized, and controlled clinical trial. Radiology. 2003;226(2):425-31.

8. Spies JB, Cooper JM, Worthington-Kirsch R, Lipman JC, Mills BB, Benenati JF. Outcome of uterine embolization and hysterectomy for leiomyomas: results of a multicenter study. Am J Obstet Gynecol. 2004;191(1):22-31.

9. Dutton S, Hirst A, McPherson K, Nicholson T, Maresh M. A UK multicentre retrospective cohort study comparing hysterectomy and uterine artery embolisation for the treatment of symptomatic uterine fibroids (HOPEFUL study): main results on medium-term safety and efficacy. BJOG. 2007;114(11): 1340-51.

10. Oriol NE, Cote PJ, Vavasis AP, Bennet J, Delorenzo D, Blanc P, et al. Calculating the return on investment of mobile healthcare. BMC Med. 2009;7:27.

11. Naeim A, Keeler E, Bassett LW, Parikh J, Bastani R, Reuben DB. Costeffectiveness of increasing access to mammography through mobile mammography for older women. J Am Geriatr Soc. 2009;57(2):285-90.

12. Portnoi LM, Dibirov MP, Denisova LB. [Diagnostic perspectives of mobile radiographic computerized tomography]. Vestn Rentgenol Radiol. 1992;(4):44-8.

13. Spies JB, Myers ER, Worthington-Kirsch R, Mulgund J, Goodwin S, Mauro $\mathrm{M}$; FIBROID Registry Investigators. The FIBROID Registry: symptom and quality-of-life status 1 year after therapy. Obstet Gynecol. 2005;106(6): 1309-18. 
14. Hovsepian DM, Siskin GP, Bonn J, Cardella JF, Clark TW, Lampmann LE, et al. Quality improvement guidelines for uterine artery embolization for symptomatic leiomyomata. J Vasc Interv Radiol. 2004;15(6):535-41.

15. Worthington-Kirsch R, Spies JB, Myers ER, Mulgund J, Mauro M, Pron G, et al. The Fibroid Registry for outcomes data (FIBROID) for uterine embolization: short-term outcomes. Obstet Gynecol. 2005;106(1):52-9.
16. White AM, Banovac F, Spies JB. Patient radiation exposure during uterine fibroid embolization and the dose attributable to aortography. J Vasc Interv Radiol. 2007;18(4):573-6.

17. Spies JB, Spector A, Roth AR, Baker CM, Mauro L, Murphy-Skrynarz K. Complications after uterine artery embolization for leiomyomas. Obstet Gynecol. 2002;100(5 Pt 1):873-80. 